\title{
Cluster headache in women: clinical characteristics and comparison with cluster headache in men
}

\author{
T D Rozen, R M Niknam, A L Shechter, W B Young, S D Silberstein
}

\begin{abstract}
Objective-To study the clinical characteristics of cluster headache in women. Cluster headache is a disorder of men (male to female ratio 6-7:1).

Methods-Retrospective chart review to identify all women diagnosed with cluster headache at an academic headache centre from January 1995 through July 1998. Results-Thirty two women and 69 men were identified. The mean age of onset of cluster headache was 29.4 years in women versus 31.3 years in men. Two peaks of onset in women ( 2 nd and 5 th decade) were identified compared with one in men (3rd decade). Episodic cluster headache was present in $75 \%$ of women and $77 \%$ of men. Women and men had on average 3 attacks a day, but attack duration was shorter in women (67.2 minutes $v 88.2$ minutes). Cluster headache period duration (11.1 weeks $v 10$ weeks) and remission periods (21.1 months $v 23.1$ months) were similar in women and men. Miosis and ptosis seemed to be less common in women (miosis $13.3 \%$ v $24.6 \%$, ptosis $41.9 \% v$ $58.1 \%$ ) whereas lacrimation and nasal congestion/rhinorrhoea were almost equally prevalent in women and men. Women had more nausea than men $(62.5 \%$ $v 43.5 \%, p=0.09)$ and significantly more vomiting $(46.9 \% v 17.4 \%, p=0.003)$. Photophobia occurred in $75 \%$ of women and $81.2 \%$ of men, and phonophobia occurred in $50 \%$ of women and $47.8 \%$ of men.

Conclusions-The clinical characteristics of cluster headache in women are very similar to those in men. Women develop the disorder at an earlier age of onset and experience more "migrainous symptoms" with cluster headache, especially vomiting. Both men and women have frequent photophobia and phonophobia with cluster headache attacks. These symptoms are not included in the International Headache Society cluster headache criteria, suggesting the need for possible criteria revision.

(F Neurol Neurosurg Psychiatry 2001;70:613-617)
\end{abstract}

Keywords: cluster headache; women; sex; autonomic symptoms

Correspondence to:

Dr T D Rozen

todd.rozen@mail.tju.edu

Received 26 April 2000 and in revised form

23 November 2000

Accepted 11 January 2001 always been identified as a disorder of men, with a male to female ratio of $6-7: 1{ }^{1}$ Most of the accepted clinical characteristics of cluster headache have been established through observation of men with this disorder. Very few studies have been dedicated to describing the disorder in women because of its rarity. Manzoni ${ }^{1}$ has suggested that the sex ratio for cluster headache is decreasing and that more women are developing or being diagnosed with cluster headache. We attempted to better define the clinical characteristics of cluster headache in women and compare and contrast these manifestations with those in men.

Patients and methods

We carried out a retrospective chart review at the Jefferson Headache Center (a university based academic headache clinic) to identify all women diagnosed with cluster headache from January 1995 to the end of July 1998. Each patient had to satisfy the International Headache Society (IHS) criteria for cluster headache $^{2}$ : at least five attacks of severe unilateral, orbital, supraorbital, and/or temporal pain that last from 15 to 180 minutes untreated. The headache needed to be associated with at least one of the following signs or symptoms: lacrimation, conjunctival injection, rhinorrhea, nasal congestion, forehead and facial sweating, miosis, ptosis, or eyelid oedema. A total of 32 women were identified. A sample of 69 male patients with cluster headache, who were diagnosed during the same time period, was obtained for clinical comparison. These male patients represented the most recent seen with cluster headache at the Jefferson Headache Center and did not represent the entire male cohort diagnosed during the study period. All of the patients included in the study were diagnosed by a neurologist with expertise in headache. Using a uniform questionnaire, we evaluated patient demographics (age of onset of cluster headache, race, cluster headache type), cluster headache attack characteristics (frequency, duration), and associated symptoms. The IHS criteria symptoms for cluster headache were collected, as well as so called "migrainous symptoms," including nausea, vomiting, photophobia, and phonophobia, which in the past were not thought to be typical of cluster headache and are not part of the IHS criteria. If the chart was not complete, patients were contacted by telephone to obtain the missing data. 
Table 1 Cluster study: demographics

\begin{tabular}{llll}
\hline & Women & Men & p Value \\
\hline $\begin{array}{l}\text { Age of onset (y) (mean (SD)) } \\
\text { Race (\%): }\end{array}$ & $29.4(15.9)$ & $31.3(13.5)$ & 0.542 \\
$\quad$ White & 75.0 & 82.6 & 0.372 \\
$\quad$ Black & 25.0 & 17.4 & \\
Type (\%): & 75.0 & 76.8 & 0.842 \\
$\quad$ Episodic & 25.0 & 23.2 & \\
Chronic & & & \\
\hline
\end{tabular}

STATISTICAL ANALYSIS

A $\chi^{2}$ analysis was used for categorical data, and $t$ testing was used for continuous variables. A p value $<0.05$ was considered significant.

\section{Results}

Thirty two women and 69 men were identified. The mean age of onset of cluster headache was 29.4 years in women versus 31.3 years in men (table 1). Most women had developed their first ever cluster headache by the age of 20, whereas most men developed their first cluster headache by the age of 25 (fig $1 \mathrm{~A}$ and B) Women had a peak of onset around the age of 20 ; a second peak, noted around the age of 50, may have been artifactual as it encompassed only three of 32 patients. Men had one peak of onset in the 3 rd decade.

In our series, $75 \%$ of women and $82.6 \%$ of men were white, whereas more AfricanAmerican women had cluster headache than African-American men (25\% v 17.4\%) (table 1). Episodic cluster headache (more than 14 headache free days a year) was present in $75 \%$ of women and $76.8 \%$ of men. Chronic cluster headache occurred in the remainder $(25 \%$ and $23.2 \%$ respectively) (table 1 ). Both women and men averaged about three attacks a day (women 3.2, men 3.0), but the duration of each individual attack was shorter in women (67.2 minutes) than in men (88.2 minutes) $(p=0.074)$ (table 2). Cluster headache period duration was not significantly different in women and men (11.1 weeks $v 10$ weeks). Average remission times were almost equal in women (21.1 months) and men (23.1 months). Miosis and ptosis were slightly less common in women than in men (miosis $13.3 \%$ v 24.6; ptosis $41.9 \%$ v $58.1 \%$ ). Lacrimation (women $79.3 \%$, men $83.8 \%$ ) and nasal congestion/ rhinorrhoea (women $87.5 \%$, men $82.6 \%$ ) were almost equally prevalent in women and men (table 3). Women experienced more nausea than men $(62.5 \%$ v $43.5 \%, \mathrm{p}=0.09)$ and

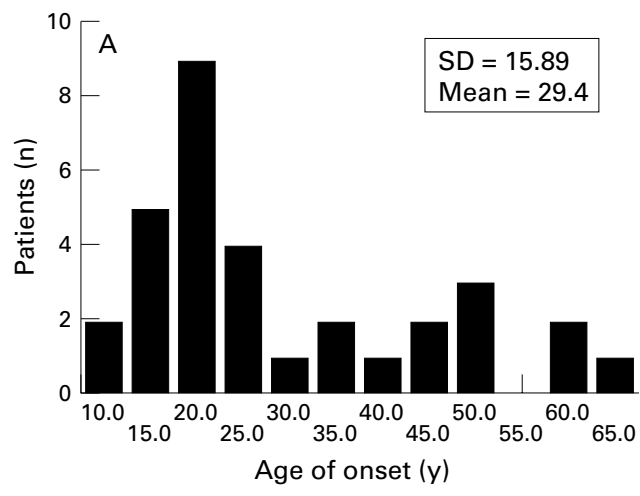

significantly more vomiting $(46.9 \%$ v $17.4 \%$, $\mathrm{p}=0.003$ ). Photophobia occurred in $75 \%$ of women and $81.2 \%$ of men, and phonophobia occurred in $50 \%$ of women and $47.8 \%$ of men (table 3). Six women and six men had a personal history of migraine.

Thirty four per cent of women and $45 \%$ of men stated that alcohol would induce a cluster headache, and $100 \%$ of women and $91 \%$ of men said that sleep was a trigger. A history of cigarette smoking was identified in $75 \%$ of women and $60.8 \%$ of men. Cluster headache led to disability (either needing to stop an activity or being unable to carry out an activity with typical performance) in 33\% of women and $25 \%$ of men.

\section{Discussion}

CLUSTER HEADACHE DEMOGRAPHICS

Cluster headache is primarily a disorder of men, and most of its recognised manifestations have been identified through observation of male patients. The reason for the male predominance is unknown. It may be due to male sex hormones or specific male behavioural traits. During periods of cluster headache, there is a lowering of serum testosterone concentration; this may be a cause or a consequence of the headache, and may be due to hypothalamic involvement. ${ }^{3}$ Replacement of testosterone does not lead to improvement in cluster headache, but it does lead to male hypersexuality. ${ }^{4}$ Men are more prone to head trauma, which may cause cluster headache. Freidman and Mikropoulos ${ }^{5}$ found a head injury frequency of $16 \%$ in their patients. Until recently, men have had heightened stressors of daily living (money maker, physical labourer) compared with women, and this may have predisposed them to developing cluster headache. Men also consumed more alcoholic beverages and smoked more cigarettes than women, and these social activities have been linked to genesis of the disorder. Cluster headache seems to be increasing in women, which may be secondary to women taking on the occupations and vices of men.

The disorder in women is not exactly the same as in men. It seems to start earlier in life in women and women may have two peaks of age of onset compared with only one in men. Most women will have their first ever cluster headache attack by the age of 20 , whereas men

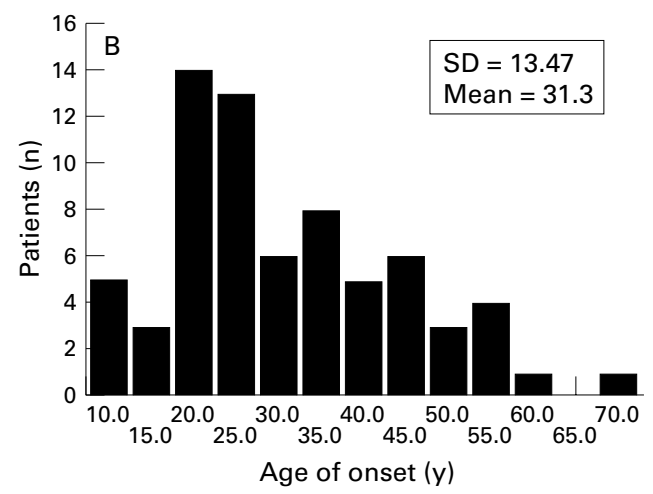

Figure 1 Age of onset of cluster headache in (A) women; (B) men. 
Table 2 Cluster attack: characteristics

\begin{tabular}{llll}
\hline & Women & Men & p Value \\
\hline Cluster attack: & $3.2(1.7)$ & $30(1.5)$ & 0.549 \\
$\quad \begin{array}{l}\text { Frequency (No/day (SD)) } \\
\quad \text { Duration (min (SD)) }\end{array}$ & $67.2(32.0)$ & $88.2(62.0)$ & 0.074 \\
$\begin{array}{l}\text { Cluster period: } \\
\quad \begin{array}{l}\text { Duration (weeks (SD)) } \\
\text { Remissions: } \\
\quad \text { Duration (months (SD)) }\end{array}\end{array}$ & $11.1(6.1)$ & $10.0(7.9)$ & 0.614 \\
\hline
\end{tabular}

Table 3 Associated symptoms

\begin{tabular}{llll}
\hline Symptom & $\begin{array}{l}\text { Women } \\
(\%)\end{array}$ & $\begin{array}{l}\text { Men } \\
(\%)\end{array}$ & p Value \\
\hline Miosis & 13.3 & 24.6 & 0.283 \\
Ptosis & 41.9 & 58.1 & 0.133 \\
Lacrimation (unilateral) & 79.3 & 83.8 & 0.770 \\
$\begin{array}{l}\text { Nasal congestion/rhinorrhoea } \\
\quad \text { unilateral) }\end{array}$ & 87.5 & 82.6 & 0.531 \\
Nausea & 62.5 & 43.5 & 0.09 \\
Vomiting & 46.9 & 17.4 & 0.003 \\
Photophobia & 75.0 & 81.2 & 0.478 \\
Phonophobia & 50.0 & 47.8 & 0.839 \\
\hline
\end{tabular}

do not develop cluster headache until after age 20 . The early development of the disorder in women has been shown in several other studies, including that performed by Ekbom, ${ }^{6}$ who found the mean age of onset in women to be 25.6 years versus 27.8 years in men, and Manzoni et $a l^{7}$, who reported the mean age of onset to be 23.3 years in women and 29.6 years in men. Two peaks of onset of cluster headache in women have been shown in two other studies: Peatfield et $a l^{\beta}$ (2nd and 5th decade) and Kudrow $^{9}$ (3rd and 6th decade). These results suggest that our findings are real and not artifacts.

Most of our patients were white, and this seems to be true of most studied cluster headache populations. The investigations generally are completed in headache clinic settings, which may bias the racial sample. Our headache centre is in a metropolitan city, which has a good racial mix, with equal access to white and African-American patients. AfricanAmerican women seem to develop cluster headache more often than African-American men $(25 \% v 17.4 \%)$, which is consistent with Kudrow's findings. ${ }^{9}$

The predominant cluster headache subtype in both our women and men was episodic, which occurred in about $75 \%$ of patients. This is the most common subtype found in most epidemiological studies and typically occurs in more than $80 \%$ of patients. ${ }^{10}$ Chronic cluster headache is rare in both men and women, with only $4 \%$ to $20 \%$ of patients having this form of the disorder. Very few studies have looked at chronic cluster headache, but the ones that have have shown it to be almost non-existent in women, with an 18:1 ratio of male to female patients. Ekbom and Waldenlind, ${ }^{11}$ as late as 1982, had not identified a single case of chronic cluster headache in women. Our study suggests that not only does chronic cluster headache occur in women but it may do so to the same extent as in men. Manzoni et al in $1988^{12}$ found 13 of 82 women with chronic cluster headache and were one of the first groups to disagree with the notion that it is rare in women. We found a 3:1 ratio of female patients with episodic to chronic cluster headache, the largest percentage of female patients with chronic cluster headache yet documented in the literature. Manzoni et $a l^{12}$ found a 5.3:1 episodic to chronic ratio in women, and Kudrow $^{9}$ found a 4.8: 1 ratio. Why was chronic cluster headache not identified more often in women in the past? It may have been misdiagnosed as chronic migraine or it may have been thought to be cluster headache but not diagnosed as such because this primary headache disorder was not supposed to occur in women.

CLUSTER HEADACHE ATTACK CHARACTERISTICS In our study, women and men had an equal mean number of attacks a day (three). The individual attack duration was shorter in women than in men (67.2 minutes $v 88$ minutes; $p=0.074)$; approaching but not reaching significance. Manzoni et $a l^{12}$ found a tendency for shorter attack duration in women, with equal attack frequency in women and men. Kudrow, ${ }^{9}$ by contrast, found that women had longer attack duration (on average $30 \mathrm{~min}-$ utes longer) than men. The period duration (11.1 weeks $v 10$ weeks) and remission times (21.1 months $v 23.1$ months) were about equal between the sexes. Most previous large scale studies on cluster headache have shown an equal period duration in women and men..$^{9-12}$ Kudrow ${ }^{9}$ found equal remission times for men and women. Cluster headache is reportedly driven or modulated by the suprachiasmatic nucleus of the hypothalamus (the circadian clock). ${ }^{10}$ Positron emission tomography studies during attacks showed an ipsilateral activation at the base of the third ventricle in the hypothalamic grey (suprachiasmatic nucleus) region. ${ }^{13}$ Human circadian rhythms are basically fixed and static. This may be why most patients have a fixed number of cluster attacks a day and periods a year during their entire life. Both women and men have the same attack characteristics; thus, generation of cluster headache attack seems to be a sex independent process that is most likely driven by the hypothalamus.

\section{ASSOCIATED SYMPTOMS}

To make a diagnosis of cluster headache, severe head pain must be accompanied by symptoms or signs of autonomic dysfunction. Studies have looked at the frequency of autonomic symptoms, but very few have looked at the sex differences for these symptoms. Based on the results from 12 large studies, the mean frequency for the typical autonomic symptoms with cluster headache are lacrimation $73 \%$, conjunctival injection $60 \%$, rhinorrhoea $22 \%$, nasal congestion $42 \%$, and partial Horner's syndrome $50 \% .^{5} 6^{9} 14-22$ Women, in our series, had less ptosis and miosis than men (not reaching significance), but an almost equal frequency of lacrimation, nasal congestion, and rhinorrhoea. This suggests that women may have less sympathetic dysfunction with cluster headache than men, but equal frequency of parasympathetic activation. Cluster headache 
in women may thus have a different final common pathway than in men.

Goadsby and Lipton ${ }^{23}$ have suggested that headache disorders with both head pain and autonomic symptoms (cluster headache, chronic paroxysmal hemicrania) can be anatomically explained by the presence of a trigeminal-autonomic reflex pathway (a brainstem connection between the trigeminal nerve and the cranial parasympathetic outflow system). Through the trigeminal-autonomic reflex, trigeminal activation leads to head pain initiation and reflex parasympathetic activation leads to autonomic symptoms. Cluster headache is marked by both parasympathetic activation (lacrimation and rhinorrhoea) and sympathetic hypofunction (Horner's syndrome). Why patients develop sympathetic dysfunction is controversial. Some headache experts think that it is secondary to an inflammatory process or venous vasculitis involving the cavernous sinus which lesions sympathetic fibres coursing through this region. ${ }^{24}$ Orbital phlebography during periods of active cluster headache demonstrates an obliterating process involving the superior ophthalmic vein and cavernous sinus, suggestive of a venous vasculitis. ${ }^{25}$ Other researchers suggest that the changes visualised in the cavernous sinus are only an epiphenomena of trigeminal activation and thus not specific to cluster headache and not the cause of sympathetic hypofunction. ${ }^{26}$ These researchers hypothesise that trigeminalautonomic reflex activation leads to carotid artery swelling, which then causes a local third order sympathetic nerve lesion that produces a partial Horner's syndrome. Further studies are necessary to determine if women have a dissociation between parasympathetic activation and sympathetic hypofunction during cluster headache. Afra et $a l^{7}$ have suggested that men may have a predisposition to developing cavernous sinus venous vasculitis and thus cluster headache because of a constitutional narrowness of their cavernous sinus region that would result in a disturbance of local venous drainage. External morphometric skull measurements were done in male patients with cluster headache, male migraineurs, and patients without headache. The patients with cluster headache had a narrower anterior/middle cranial fossa and possibly a narrower cavernous sinus loggia than migraineurs and control patients. If women do not have the same cranial structural problems as men, they are at less risk of developing venous vasculitis and thus less likely to have sympathetic dysfunction with cluster headache attacks. A craniometric study in women would answer this question.

Symptoms that are generally associated with migraine (nausea, vomiting, photophobia and

Table 4 Cluster associated symptoms versus migraine associated symptoms

\begin{tabular}{lllll}
\hline Symptom & $\begin{array}{l}\text { Rozen et al } \\
\text { (malelfemale mean) }\end{array}$ & Manzoni ${ }^{1}$ & Vingen et al $^{28}$ & $\begin{array}{c}\text { Migraine } \\
\text { (mean) }^{30}\end{array}$ \\
\hline Photophobia & $78.1 \%$ & $56 \%$ & $91 \%$ & $79 \%$ \\
Phonophobia & $48.9 \%$ & $15 \%$ & $89 \%$ & $80 \%$ \\
Nausea & $53.0 \%$ & $41 \%$ & & $87 \%$ \\
Vomiting & $32.1 \%$ & $24 \%$ & $56 \%$ \\
\hline
\end{tabular}

phonophobia, and aura) have been poorly studied in patients with cluster headache. In the 1950 s, nausea was noted in more than $20 \%$ of patients with cluster headache. ${ }^{19}{ }^{20}$ Migrainous symptoms seem to be highly prominent in patients with cluster headache, especially in women. Our female cluster headache population had more nausea and significantly more vomiting than our men. Manzoni et al $l^{12}$ also found that nausea was more common in women than men. They did not find any other sex differences in cluster headache symptoms. Nausea has been reported in $10 \%$ to $54 \%$ of patients, whereas vomiting has been noted in $1 \%$ to $15 \%$ (data from mainly male cluster headache populations). Almost $63 \%$ of our women had nausea and $47 \%$ had vomiting (table 3) This is a much higher percentage than reported in the current literature, suggesting that these symptoms are closely tied to female cluster headache alone and not male cluster headache. Photophobia and phonophobia were frequent symptoms in both men and women in our study population. This does not seem to be unique to our cohort, as Vingen $e t a l^{8}$ found a self reported frequency of photophobia in $91 \%$ of 50 patients and phonophobia in $89 \%$.

\section{SHOULD THE IHS CRITERIA FOR CLUSTER}

HEADACHE BE MODIFIED?

Many of our patients had photophobia, phonophobia, nausea, and vomiting with their headaches. These symptoms are not part of the IHS criteria for cluster headache and perhaps they should be added to make the criteria more sensitive. Can these symptoms still be used to distinguish migraine from cluster headache and tension-type headache? These symptoms may not be syndrome specific but just markers of trigeminal-autonomic pathway activation. Table 4 compares the frequency of photophobia, phonophobia, nausea, and vomiting from our own and two other cluster headache studies $^{28-29}$ with the mean frequency of these symptoms from seven migraine studies. ${ }^{30}$ Photophobia and phonophobia occurred with equal or greater frequency in cluster headache than migraine. Nausea and vomiting occurred less often in cluster headache than in migraine suggesting that these two symptoms are useful in differentiating migraine from cluster headache, but photophobia and phonophobia are not. Further studies are needed on the prevalence of "migrainous symptoms" in cluster headache before we can justify a change in the IHS criteria. However, physicians who treat patients with headache must realise that photophobia, phonophobia, nausea, and vomiting are part of the cluster headache symptom profile and that the presence of these symptoms does not eliminate cluster headache from the differential diagnosis. In addition, we have found aura in patients with cluster headache, which further blurs the boundaries between what is cluster headache and what is migraine. ${ }^{31}$ The occurrence of so called "migrainous symptoms" in cluster headache may have led to a misdiagnosis of patients with cluster headache in older epidemiological studies on 
headache, thus falsely lowering prevalence rates for cluster headache, especially in women.

Overall, the clinical characteristics of cluster headache in women are very similar to those in men, suggesting a common pathogenesis. Women seem to develop the disorder at an earlier age of onset than men and experience more "migrainous symptoms" with cluster headache, especially vomiting. Further studies of the female patient with cluster headache are necessary to better define this primary headache syndrome in women.

This material was presented in abstract form at the American Academy of Neurology 51 st Annual Meeting, Toronto, Canada, April 22,1999.

1 Headache Classification Committee of the International Headache Society. Classification and diagnostic criteria for headache disorders, cranial neuralgias and facial pain. Cephalalgia 1988; (suppl 7):1-96.

2 Kudrow L. Plasma testosterone levels in cluster headache: preliminary results. Headache 1976;16:28-31.

3 Nicolodi M, Sicuteri F, Poggioni M. Hypothalamic modulation of nociception and reproduction in cluster headache. tion of nociception and reproduction in cluster headache. II. Testosterone-induce increase of sexual activity in
with cluster headache Cephalalgia 1993;13:258-60.

4 Freidman AP, Mikropoulos HE. Cluster headaches. NeurolFreidman AP, Mikropo
ogy 1958;8:653-63.

5 Ekbom K. A clinical comparison of cluster headache and migraine. Acta Neurol Scand 1970;(suppl 41):1-44.

6 Manzoni GC, Micieli G, Granella F, et al. Cluster headache-course over 10 years in 189 patients. Cephalalgia 1991;11:169-74.

7 Peatfield RC, Petty RG, Clifford Rose F. Cluster headache in women. Cephalalgia 1982;2:171.

8 Kudrow L. Cluster headache: mechanisms and management. London: Oxford University Press, 1980.

9 Kudrow L. Cluster headache. In: Goadsby PJ, Silberstein SD, eds. Headache. Boston: Butterworth-Heinemann, 1997:227-42.

10 Ekbom K, Waldenlind E. Cluster headache in women: evidence of hypofertility(?): headaches in relation to menstruation and pregnancy. Cephalalgia 1981;1:167-74.
11 Manzoni GC, Micieli G, Granella F, et al. Cluster headache in women: clinical findings and relationship with reproducin women: clinical findings and relatior
tive life. Cephalalgia 1988;8:37-44.

12 May A, Bahra A, Buchel C, et al. Hypothalamic activation in cluster headache attacks. Lancet 1998;351:275-8.

13 Duvoisin RC, Parker GW, Kenoyer WL. The cluster headache. Arch Intern Med 1961;108:711-16.

14 Hornabrook RW. Migrainous neuralgia. New Zealand Medical fournal 1964;63:774-9.

15 Heyck H. Cluster-Kopfschmerz (Bing-Horton-Syndrom?). Fortschr Neurol Psychiatr 1976;44:37-50.

16 Robinson BW. Histamine cephalalgia. Medicine 1958;37: 161-80.

17 Manzoni GC, Terzano MG, Bono G, et al. Cluster headache: clinical findings in 180 patients. Cephalalgia 1983;3:21-30.

18 Sutherland JM, Eadie MJ. Cluster headache. Res Clin Stud Headache 1972;3:92-125.

19 Symonds C. A particular variety of headache. Brain 1956;79:217-32.

20 Lance JW, Anthony M. Migrainous neuralgia or cluster headache? F Neurol Sci 1971;13:401-14.

21 Pearce JMS. Chronic migrainous neuralgia: a variant of cluster headache. Brain 1980;103:149-59.

22 Goadsby PJ, Lipton RB. A review of paroxysmal hemicranias, SUNCT syndrome, and other short-lasting headaches with autonomic features, including new cases. Brain 1997; 120:193-209.

23 Hardebo JE. How cluster headache is explained as an intracavernous inflammatory process lesioning sympathetic fibers. Headache 1994;34:125-31.

24 Hannerz J, Ericson K, Bergstrand G. Orbital phlebography in patients with cluster headache. Cephalalgia 1987;7:20711

25 Goadsby PJ. Cluster headache: new perspectives. Cephalalgia 1999;19(suppl):39-41.

26 Afra J, Cecchini AP, Schoenen J. Craniometric measures in cluster headache patients. Cephalalgia 1998;18:143-5.

27 Vingen JV, Pareja JA, Sovner LJ. Quantitative evaluation of photophobia and phonophobia in cluster headache. Cephalalgia 1998;18:250-6.

28 Nappi G, Micieli G, Cavallini A, et al. Accompanying symptoms of cluster attacks: their relevance to the diagnostic criteria. Cephalalgia 1992;12:165-8.

29 Anthony M, Rasmussen BK. Migraine without aura. In: Olesen J, Tfelt-Hansen P, Welch KMA, eds. The headaches. New York: Raven Press, 1993:258.

30 Silberstein SD, Niknam R, Rozen TD, et al. Cluster headache with aura. Neurology 2000;54:219-21. 